\title{
Comamonas nitrativorans sp. nov., a novel denitrifier isolated from a denitrifying reactor treating landfill leachate
}

\author{
1 Departamento de \\ Microbiología, Facultad de \\ Química y Facultad de \\ Ciencias, Universidad de la \\ República, Gral. Flores \\ 2124, Montevideo, \\ Uruguay \\ 2 Institute National de la \\ Recherche Agronomique, \\ Laboratoire de \\ Biotechnologie de \\ I'Environnement, \\ Narbonne, France
}

\author{
Claudia Etchebehere, ${ }^{1}$ María I. Errazquin, ${ }^{1}$ Patrick Dabert, ${ }^{2}$ \\ René Moletta² and Lucía Muxír
}

Author for correspondence: Claudia Etchebehere. Tel: +598 29244209. Fax: +59829241906. e-mail: cetchebe@bilbo.edu.uy

\begin{abstract}
A group of Gram-negative denitrifying bacteria has been isolated from a denitrifying reactor treating landfill leachate. The new isolates produced both oxidase and catalase and showed growth on acetate, butyrate, n-caproate, i-butyrate, i-valerate, propionate, $n$-valerate, lactate, alanine, benzoate, phenylalanine and ethanol. No growth was observed on sugars. The bacteria could perform anoxic reduction of nitrate, nitrite and nitrous oxide to nitrogen, coupled to the oxidation of the same substrates as those used under aerobic conditions, except for aromatic compounds. They were very efficient denitrifiers, as estimated from the specific rate of $\mathrm{N}_{2}$ gas production. All the strains showed the same 165 rDNA restriction profile and one of them, designated $23310^{\top}$, was selected for phylogenetic analysis. The organism clustered within the family Comamonadaceae, being related to Comamonas terrigena ( $95.8 \%$ sequence similarity). On the basis of the phylogenetic analysis, physiological characterization and the ability to efficiently reduce nitrate to $\mathrm{N}_{2}$, it is proposed that the bacterium be assigned to a new species, Comamonas nitrativorans. The type strain is $23310^{\top}$ ( $=$ DSM $13191^{\top}=$ NCCB $100007^{\top}=$ (CT $7062^{\top}$ ).
\end{abstract}

Keywords: Comamonadaceae, denitrification, specific denitrifying activity

\section{INTRODUCTION}

The need for the removal of inorganic nitrogen compounds from waste waters is being increasingly recognized. Ammonium removal can be accomplished by a combination of the biological processes of nitrification and denitrification, which convert it into gaseous products. Information on the microbiota present in denitrifying reactors is still scarce; a better understanding of the nature of nitrate-reducing organisms will contribute to an improvement in the operation and performance of these reactors.

Denitrifying bacteria belong to a biochemically and taxonomically diverse group of facultatively anaerobic bacteria, characterized by the ability to use nitrogen oxides (nitrate and nitrite) as electron acceptors, producing mainly $\mathrm{N}_{2}$ as reduction product (Knowles,

Abbreviation: ARDRA, amplified 16S rDNA restriction analysis.

The EMBL accession number for the $16 \mathrm{~S}$ rDNA sequence of strain $23310^{\top}$ is AJ251577.
1982). According to Mahne \& Tiedje (1995) two criteria should be met to conclusively establish if an organism is a respiratory denitrifier, namely, that nitrogen recovery as $\mathrm{N}_{2}$ plus $\mathrm{N}_{2} \mathrm{O}$ from nitrate should exceed $80 \%$ and that the rate of $\mathrm{N}_{2}$ gas production should exceed $10 \mu \mathrm{mol} \mathrm{min}{ }^{-1}$ (g protein $)^{-1}$. Up to the last decade the most frequently isolated denitrifiers were classified as Alcaligenes, Paracoccus, Pseudomonas and Rhodobacter (Zumft, 1992); however, with the development of a classification based on $16 \mathrm{~S}$ rDNA phylogenetic analysis, many denitrifying isolates have been shown to belong to new genera. Furthermore, organisms previously classified in the genus Pseudomonas were assigned to new genera (Anders et al., 1995).

During the characterization of the microflora of a denitrifying reactor treating landfill leachate we isolated a group of bacteria which persisted in the reactor and showed a high specific denitrifying activity. In this study the characterization of one of the strains is presented and, based on phenotypic and phylo- 
genetic properties, it is described as a novel species within the genus Comamonas for which we propose the name Comamonas nitrativorans.

\section{METHODS}

Bacterial strains and culture conditions. The strains used in this study were isolated from sludge samples of the anoxic reactor of a laboratory scale combination of three reactors methanogenic, anoxic and aerobic - for carbon and nitrogen removal from the leachate of the sanitary landfill in the city of Montevideo (Borzacconi, 1998). The denitrifying reactor was fed with leachate and $\mathrm{KNO}_{3}[\mathrm{C} / \mathrm{N}=4 \mathrm{~g}$ chemical oxygen demand (COD) $\left(\mathrm{g} \mathrm{N} / \mathrm{NO}_{3}^{-}\right)^{-1}$ ] for the first year and with effluent from the methanogenic reactor and $\mathrm{KNO}_{3}$ for the following 9 months. Samples were taken from the sludge and denitrifiers were enumerated by Most Probable Number (MPN) in a basal medium supplemented with potassium acetate $\left(1.84 \mathrm{~g}^{-1}\right)$ and potassium nitrate $\left(0.72 \mathrm{~g} \mathrm{l}^{-1}\right)$ (BCY acetate-nitrate) under an atmosphere of $\mathrm{N}_{2}$, as previously described (Quevedo et al., 1996). Acetylene (10\%, v/v) was added to the headspace and tubes were considered positive for denitrification when accumulation of $\mathrm{N}_{2} \mathrm{O}$ occurred in the headspace. The predominant denitrifiers were isolated from the positive tubes of the highest dilution of the MPN enumeration on Trypticase Soy Agar (TSA; Difco). The ability of pure cultures to denitrify was confirmed by $\mathrm{N}_{2} \mathrm{O}$ accumulation when grown in BCY acetate-nitrate, under an atmosphere of $\mathrm{N}_{2}$ with acetylene $(10 \%)$. The isolates with the ability to denitrify were stored in Trypticase Soy Broth (TSB; Difco) supplemented with glycerol $(20 \%, \mathrm{v} / \mathrm{v})$ at $-70{ }^{\circ} \mathrm{C}$.

Amplified 16S rDNA restriction analysis (ARDRA). The bacterial isolates (18 strains) were differentiated by determining their ARDRA profiles. ARDRA was carried out as described by Fernandez et al. (1999) with primers specific for the 16S rRNA gene of the domain Bacteria, using HhaI and HaeIII restriction enzymes (Amersham). Restriction patterns were normalized and compared by GelCompar software (version 4.1; Applied Maths). Pattern clustering was done by the UPGMA method applying the Dice coefficient. A maximum tolerance of $3.0 \pm 0.5 \%$ was used for band positions.

Phenotypic characterization. The strains were preliminarily characterized by Gram staining, an oxidation-fermentation test, presence of catalase and oxidase (Smibert \& Krieg, 1994) and a VITEK GNI + (bioMérieux) characterization kit. Cell morphology and motility were studied by phasecontrast microscopy (Axioplan; Zeiss). Tests for growth on different substrates were performed aerobically in tubes with $10 \mathrm{ml}$ of a basal BCY medium (Quevedo et al., 1996) supplemented with $5 \mathrm{mM}$ of the respective substrate and anaerobically under an $\mathrm{N}_{2}$ atmosphere in the same medium also supplemented with potassium nitrate $(5 \mathrm{mM})$. All growth tests were performed in duplicate.

The optimum temperature for growth was determined aerobically in duplicate in tubes with $10 \mathrm{ml}$ TSB at different incubation temperatures $\left(25,30,35,40,45\right.$ and $\left.55^{\circ} \mathrm{C}\right)$. The optimum $\mathrm{pH}$ was determined in TSB, previously adjusted to $\mathrm{pH}$ values ranging from 4 to 9 , incubated at $35^{\circ} \mathrm{C}$. Growth was measured spectrophotometrically (Genesys 5; Spectronic) at $660 \mathrm{~nm}$.

Electron microscopy. For ultrathin section microscopy, bacterial cultures were centrifuged at 3000 r.p.m. for 6 min at $4{ }^{\circ} \mathrm{C}$, the supernatant was discarded and the pellet was fixed in $2.5 \%(\mathrm{w} / \mathrm{v})$ glutaraldehyde and $2 \%(\mathrm{w} / \mathrm{v})$ paraformaldehyde in $0 \cdot 1 \mathrm{M}$ potassium phosphate buffer $(\mathrm{pH} \mathrm{7 \cdot 4)}$ for $2 \mathrm{~h}$. Samples were post-fixed in $1.0 \%(\mathrm{w} / \mathrm{v})$ osmium tetroxide, dehydrated in an ascending gradient of ethanol $(50,70,80,90$ and $95 \%, \mathrm{v} / \mathrm{v})$ and impregnated in propylene oxide. Finally, they were embedded in Poly/Bed 812 resin (Polysciences 18976-2590). Ultrathin sections were cut with an ultratome Super Nova (Reichter-Jung), stained with uranyl acetate and lead citrate, and examined under a JEM1200 EX II (JEOL) transmission electron microscope. For negative staining the cell pellet was resuspended in PBS and mixed with an equal volume of $3 \%(\mathrm{w} / \mathrm{v})$ phosphotungstic acid (pH 6.5). A drop of this mixture was placed on a carbon/Formvar-coated 200 mesh copper grid. Grids were air-dried before examination in the transmission electron microscope.

Analyses of isoprenoid quinones. Quinones were characterized by HPLC using an EcoCart 125-3 (Lichrospher; RP$18,5 \mu \mathrm{m})$ column and acetonitrile/2-propanol $(65: 35, \mathrm{v} / \mathrm{v})$ as mobile phase at a flow rate of $0.5 \mathrm{ml} \mathrm{min}^{-1}$. The column was kept at $40^{\circ} \mathrm{C}$. The ubiquinone was detected by a UV detector at $254 \mathrm{~nm}$ (Kroppenstedt, 1985). The analyses were performed at the DSMZ (Deutsche Sammlung von Mikroorganismen und Zellkulturen, Braunschweig, Germany).

Denitrifying activity. The specific denitrifying activity of the strains was measured by specific $\mathrm{N}_{2} \mathrm{O}$ production rates by resting cells, using a modification of the method described by Mahne \& Tiedje (1995). Briefly, the bacteria were grown in BCY acetate-nitrate medium under an $\mathrm{N}_{2}$ atmosphere, anaerobically centrifuged (10000 r.p.m., $15 \mathrm{~min}$ ) and resuspended in anaerobic potassium phosphate buffer ( $50 \mathrm{mM}, \mathrm{pH} 7 \cdot 0)$. After determination of the protein concentration, the suspension was anaerobically dispensed under an $\mathrm{N}_{2}$ atmosphere into $10 \mathrm{ml}$ vials to give $0.7-1.5 \mathrm{mg}$ protein. Then it was diluted to $4 \mathrm{ml}$ with the same anaerobic potassium phosphate buffer supplemented with chloramphenicol $\left(100 \mu \mathrm{g} \mathrm{ml}^{-1}\right)$. The vials were capped and acetylene $(10 \%)$ was added to the headspace. The assay mixture was magnetically stirred and, at time zero, nitrate $(4 \mu \mathrm{mol})$ and potassium acetate $(8 \mu \mathrm{mol})$ were added from an anaerobic stock solution. $\mathrm{N}_{2} \mathrm{O}$ was measured at intervals in samples of the headspace, taken with a gas-tight syringe (Hamilton). The specific denitrifying activity was calculated from the slope of the curve of $\mathrm{N}_{2} \mathrm{O}$ production versus time and expressed as $\mu \mathrm{mol} \mathrm{N}_{2} \mathrm{O}$ (g protein) ${ }^{-1} \mathrm{~min}^{-1}$. The specific denitrifying activity was also measured in TSB nitrate medium as described by Mahne \& Tiedje (1995). All experiments were performed by duplicate and the standard deviation was always less than $5 \%$

Aerobic denitrification. The ability to respire nitrogen oxides in the presence of oxygen was tested in batch cultures by measuring the reduction of nitrate under anoxic and aerobic conditions, according to the method described by Patureau et al. (1998). The strains were inoculated (1\%) into BCY acetate-nitrate and incubated with agitation (8000 r.p.m.) under anoxic and aerobic conditions at $35^{\circ} \mathrm{C}$. Nitrate concentrations were measured during growth.

Analytical procedures. Nitrate and nitrite were measured in the supernatant of centrifuged (10000 r.p.m.) samples by HPLC (Waters) using an IC-Pack Anion column (Waters) and UV detector (Shimadzu) at $210 \mathrm{~nm}$. The solvent was potassium phosphate buffer $(0.01 \mathrm{M}, \mathrm{pH} 6.8)$ at a flow rate of $1.2 \mathrm{ml} \mathrm{min}^{-1}$. The column was kept at $40{ }^{\circ} \mathrm{C} . \mathrm{N}_{2} \mathrm{O}$ was measured by GC (Chrompack CP90001) with an electron 
capture detector operating at $300^{\circ} \mathrm{C}$ and with a Porapak Q 80100 (Chrompack) column. The carrier gas was $\mathrm{N}_{2}$ and the oven temperature was $55^{\circ} \mathrm{C}$. The total $\mathrm{N}_{2} \mathrm{O}$ content was calculated from the headspace concentration as described by Christensen \& Tiedje (1988). Proteins were measured using the Lowry method with bovine serum albumin as standard (Daniels et al., 1994).

16S rDNA sequence analysis. The extraction of genomic DNA from strain $23310^{\mathrm{T}}$ and the following PCR-mediated 16S rDNA amplification were performed as described by Sambrook et al. (1989) and Godon et al. (1997). Bacterial universal primers used for PCR were: forward $27 \mathrm{~F}$ (5'AGAGTTTGATCCTGGCTCAG-3'), corresponding to positions 8-27 (Escherichia coli numbering); and reverse 1522R (5'-AAGGAGGTGATCCAGCCGCA-3'), corresponding to positions $1522-1542$. The PCR product was sequenced with the dye-terminator cycle-sequencing readyreaction kit, with AmpliTaq DNA polymerase FS (PerkinElmer). Sequence reaction mixtures were electrophoresed on an Applied Biosystems/Perkin-Elmer model 373A sequencer. The $16 \mathrm{~S}$ rDNA sequence was compared with all accessible sequences in databases using the BLAST server at NCBI (National Centre for Biotechnology Information, Bethesda, MD, USA). The sequence was aligned with sequences belonging to representative organisms of the $\beta$ subclass of the Proteobacteria. The alignments were performed and corrected by using CLUSTAL w and Seq-pup software. An unrooted tree was constructed using DNADIST (Jukes \& Cantor algorithm) and neighbour-joining programs contained in the PHYLIP Phylogeny Inference Package, version 3.5 (Felsenstein, 1993). A bootstrap analysis of 100 replicates was also performed using programs included in the same package.

\section{RESULTS}

\section{Screening of the isolates by ARDRA}

The reactor was sampled six times during 1 year of operation; the 18 denitrifying strains isolated clustered in nine different ARDRA profiles. Strain $\mathrm{K}$ and strains $23310^{\mathrm{T}}$ and 6 (isolated 8 and 9 months later than strain $\mathrm{K}$, respectively) shared the same ARDRA profile (Fig. 1) and were selected for further characterization.

\section{Morphological characteristics}

The three strains showed similar morphological characteristics. Strain $23310^{\mathrm{T}}$ was a very motile, Gramnegative, slightly curved rod. Cells occurred singly or in pairs in young cultures. Colonies on TSA developed after a $24 \mathrm{~h}$ incubation period and were circular (1-2 mm diameter) and cream-coloured. Electron microscopy of thin sections of strain $23310^{\mathrm{T}}$ revealed a typical Gram-negative cell wall structure with an undulating outer membrane. Cells presented flagella in bipolar tufts as shown by negative staining electron microscopy (Fig. 2).

\section{Analyses of quinones}

HPLC analysis of quinones from strain $23310^{\mathrm{T}}$ revealed a unique peak corresponding to ubiquinone Q-8.

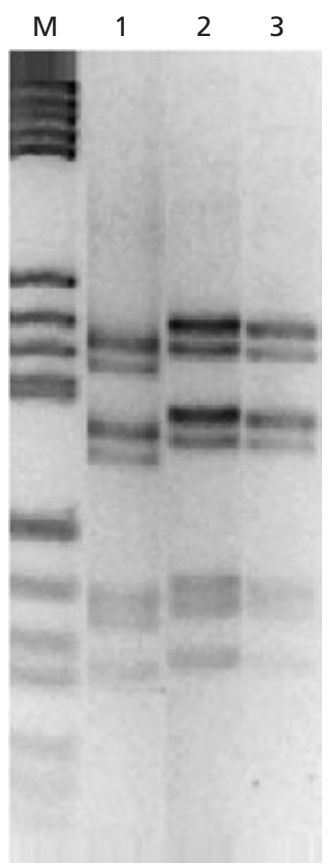

Fig. 1. ARDRA profile of strains $K$ (lane 1) 6 (lane 2) and $23310^{\top}$ (lane 3). Lane M, Smart Ladder DNA molecular mass marker (Eurogentec).

\section{Physiological characterization}

Strains $23310^{\mathrm{T}}$, 6 and $\mathrm{K}$ were heterotrophic microorganisms able to grow under aerobic and anoxic conditions. Under anoxic conditions nitrate, nitrite and $\mathrm{N}_{2} \mathrm{O}$ were reduced to $\mathrm{N}_{2}$; no $\mathrm{N}_{2} \mathrm{O}$ was detected during growth in the absence of acetylene. They presented positive tests for oxidase and catalase, and were inactive in the oxidation fermentation test with glucose as substrate. The VITEK GNI + test failed to identify the isolates, as the strains did not produce an adequate number of reactions on the GNI + card to distinguish them from other glucose non-fermenting Gram-negative bacilli. As shown in Table 1, the three strains oxidized several organic acids and some amino acids, but no sugars. Under anaerobic conditions with nitrate as electron acceptor, growth was observed with the same substrates as the ones used under aerobic conditions, except for the aromatic compounds (benzoate, phenylalanine). The optimum temperature for growth of strain $23310^{\mathrm{T}}$ was between 30 and $35^{\circ} \mathrm{C}$, but no growth was detected at $55^{\circ} \mathrm{C}$. Growth was observed between $\mathrm{pH} 5$ and 9 with an optimum at $\mathrm{pH} 7$.

\section{Denitrifying ability}

The three strains showed $\mathrm{N}_{2} \mathrm{O}$ accumulation when grown in BCY supplemented with acetate and nitrate under an $\mathrm{N}_{2}$ atmosphere in the presence of acetylene. To confirm the ability to perform respiratory denitrification, the rate of $\mathrm{N}_{2} \mathrm{O}$ production by resting cells was evaluated in the presence of acetylene (Mahne \& 


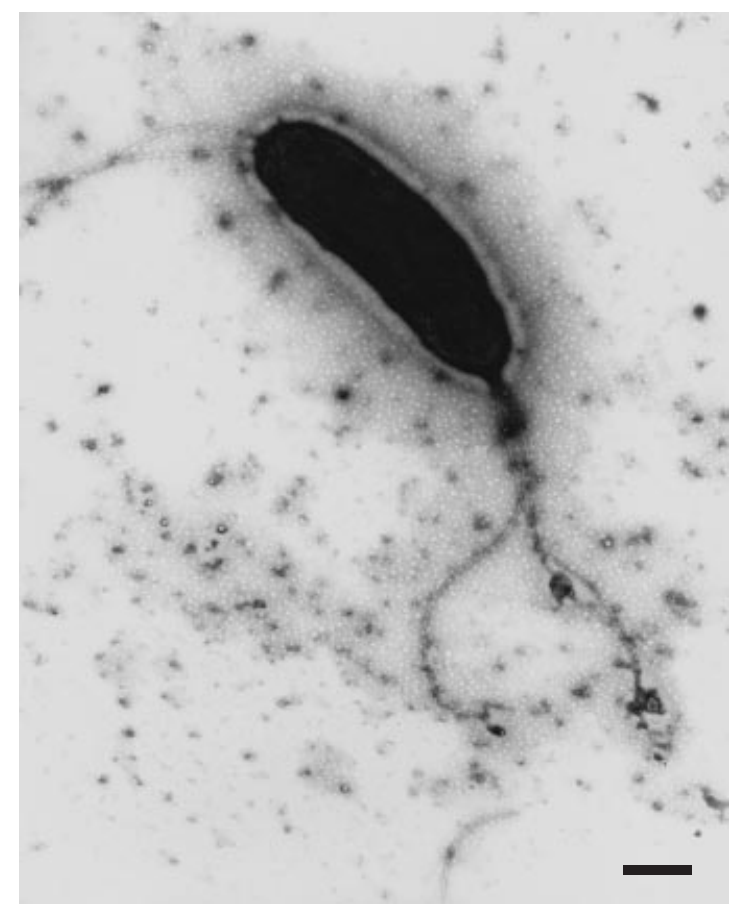

Fig. 2. Negative staining electron micrograph of strain $23310^{\top}$ showing the presence of two tufts of bipolar flagella. Bar, $0.5 \mu \mathrm{m}$.

Tiedje, 1995). The three strains showed no significant differences in the specific rate of $\mathrm{N}_{2} \mathrm{O}$ production with acetate as electron donor $\left[98 \pm 3 \mu \mathrm{mol} \mathrm{N}_{2} \mathrm{O}(\mathrm{g}\right.$

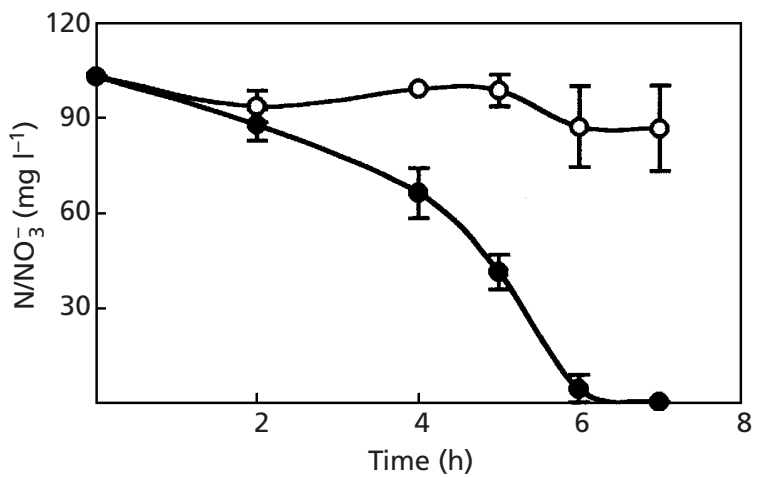

Fig. 3. Nitrate reduction in batch cultures with strain $23310^{\top}$ in $\mathrm{BCY}$ acetate-nitrate medium. $\bullet$, Anoxic conditions; $\bigcirc$, aerobic conditions. Data are means \pm SD of a duplicate assay.

protein $)^{-1} \min ^{-1}$ ] with almost complete nitrogen recuperation as $\mathrm{N}_{2} \mathrm{O}$. The denitrification rate in TSB for strain $23310^{\mathrm{T}}$ was $183 \pm 8 \mu \mathrm{mol} \mathrm{N}_{2} \mathrm{O}$ (g protein $)^{-1} \min ^{-1}$.

\section{Aerobic denitrification}

The ability to co-respire oxygen and nitrate was tested for strain $23310^{\mathrm{T}}$. Fig. 3 shows that there was no reduction of nitrate under aerobic conditions, whereas total nitrate depletion occurred under anoxic conditions in $6 \mathrm{~h}$.

Table 1. General and nutritional characteristics of strains $23310^{\top}, 6$ and $\mathrm{K}$ and comparison with members of the genus Comamonas

All strains were positive for propionate, lactate but negative for glucose, arabinose, fructose, galactose, xylose, mannitol, malonate, tartrate and $p$-aminobenzoate. W, Weak; NR, not reported.

\begin{tabular}{|c|c|c|c|}
\hline Character & Strains $23310^{\mathrm{T}}, 6 \& \mathrm{~K}$ & C. terrigena* & C. testosteroni $\dagger$ \\
\hline Nitrate to $\mathrm{N}_{2}$ & + & - & - \\
\hline \multicolumn{4}{|l|}{ Growth on: } \\
\hline Acetate & + & + & \pm \\
\hline Gluconate & - & + & + \\
\hline Butyrate & + & + & NR \\
\hline Caproate & + & - & NR \\
\hline i-Butyrate & + & + & NR \\
\hline i-Valerate & + & + & NR \\
\hline n-Valerate & + & + & NR \\
\hline Maleate & w & w & NR \\
\hline Pyruvate & - & + & NR \\
\hline Alanine & + & + & - \\
\hline Citrate & - & - & + \\
\hline Benzoate & + & - & + \\
\hline L-Phenylalanine & + & - & - \\
\hline Ethanol & + & NR & - \\
\hline
\end{tabular}

* Data from De Vos et al. (1985).

† Data from Tamaoka et al. (1987) and Patureau et al. (1998). 


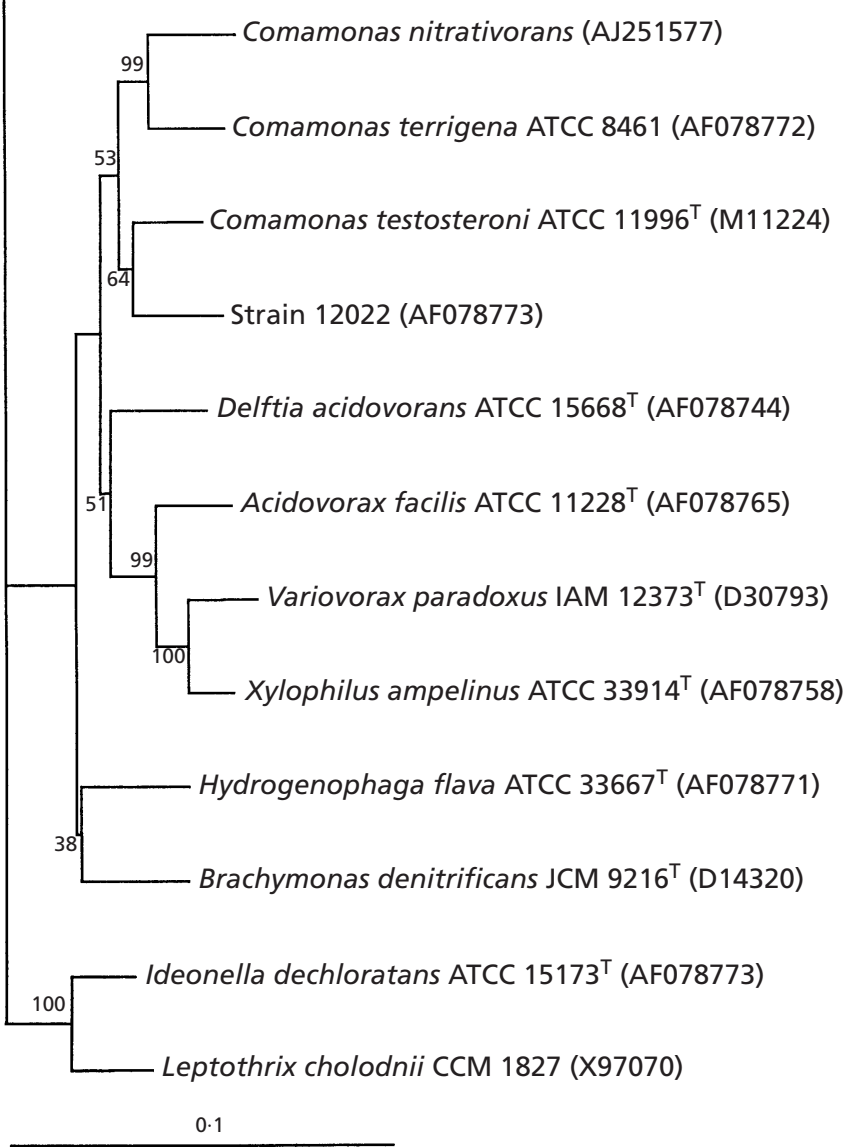

Fig. 4. Phylogenetic dendrogram derived from $16 \mathrm{~S}$ rDNA sequence analysis, showing the position of strain $23310^{\top}$ within the genus Comamonas in the family Comamonadaceae. Numbers at branches represent bootstrap values (percentages; 100 replicates). The sequence from Paracoccus versutus was used as outgroup. The bar corresponds to an evolutionary distance of $0 \cdot 1$.

\section{Phylogenetic analysis}

A total of $1498 \mathrm{nt}$ of the $16 \mathrm{~S}$ rDNA of strain $23310^{\mathrm{T}}$ was sequenced. Comparison with rDNA sequences available in databases revealed that strain $23310^{\mathrm{T}}$ was related to sequences belonging to the genus Comamonas in the $\beta$-subclass of the Proteobacteria. An evolutionary distance phylogenetic dendrogram (Jukes \& Cantor) was constructed with the neighbour-joining method using 1405 unambiguously aligned positions. $16 \mathrm{~S}$ rDNA similarity values between the sequence of strain $23310^{\mathrm{T}}$ and the sequences included in the analysis were $95.8 \%$ for Comamonas terrigena, ATCC $8451^{\mathrm{T}}, 94.5 \%$ for Comamonas testosteroni ATCC $11996^{\mathrm{T}}$ and $94.4 \%$ for strain 12022 . According to the phylogenetic analysis, strain $23310^{\mathrm{T}}$ and $C$. terrigena are in the same branch supported by a high bootstrap value of $99 \%$ (Fig. 4).

\section{DISCUSSION}

Strains $23310^{\mathrm{T}}, \mathrm{K}$ and 6 were isolated at different times during the operation of the denitrifying reactor. They shared the same ARDRA profile (Fig. 1) and the same substrate range and showed similar specific denitrifying rates. These results suggest that the three strains may be different isolates belonging to the same species, which persisted in the reactor, and probably play an important role in this denitrifying ecosystem. However, further studies are needed to demonstrate if the three strains are a single species. Commercial identification kits failed to identify these environmental strains, probably due to their physiological incapacity to grow on sugars.

The 16S rDNA phylogenetic analysis clearly showed the position of strain $23310^{\mathrm{T}}$, within the family Comamonadaceae, in the genus Comamonas (Fig. 4). Recently, a report about the phylogenetic relationships among members of the Comamonadaceae showed that $C$. testosteroni and $C$. terrigena form a deeply branched cluster and that Comamonas acidovorans (now Delftia acidovorans) occurs on a very deep branch and cannot be considered a member of the genus Comamonas (Wen et al., 1999). According to this, the genus Comamonas is represented by only two species, $C$. terrigena and $C$. testosteroni and by the as yet unidentified strain Comamonas sp. strain 12022 (Koivula \& Hantula, 1997). A third species, Comamonas denitrificans, has now been described by Gumaelius et al. (2001). The similarity values between the sequence of strain $23310^{\mathrm{T}}$ and the sequences belonging to $C$. terrigena and $C$. testosteroni demonstrate that it represents a new species in this genus. 
Several physiological differences between strain $23310^{\mathrm{T}}$ and the other representatives of the genus Comamonas confirm this result. Strain $23310^{\mathrm{T}}$ showed the ability to denitrify in BCY acetate-nitrate, accumulating $\mathrm{N}_{2} \mathrm{O}$ during growth with acetate and nitrate in the presence of acetylene, an inhibitor of the last step of denitrification. This trait was confirmed by the high specific rate of $\mathrm{N}_{2} \mathrm{O}$ production by resting cells, compared to the data reported by Mahne \& Tiedje (1995), and by the wide range of substrates utilized under denitrifying conditions. Neither C. terrigena nor C. testosteroni show this capacity (Wen et al., 1999). Currently, the only denitrifying micro-organisms described within the family Comamonadaceae are Brachymonas denitrificans (Hiraishi et al., 1995), phylogenetically distant from strain $23310^{\mathrm{T}}$ (Fig. 4), and $C$. denitrificans (Gumaelius et al., 2001).

Recently, it has been shown that some organisms can reduce oxygen and nitrate simultaneously up to oxygen-saturated conditions (Robertson et al., 1988, 1989, 1995; Patureau et al., 1998). However, no corespiration of nitrate and oxygen was detected for strain $23310^{\mathrm{T}}$. This trait has been shown for Paracoccus pantotropha (Robertson \& Kuenen, 1984; Rainey et al., 1999), Microvirgula aerodenitrificans (Patureau et al., 1998) and the recently characterized Thauera mechernichensis (Scholten et al., 1999) which were isolated from denitrifying environments exposed to oxygen. Strain $23310^{\mathrm{T}}$ was isolated from a reactor maintained under anoxic conditions for a long time; probably the property of aerobic denitrification was not selected in this reactor.

Strain $23310^{\mathrm{T}}$, like C. terrigena and C. testosteroni, presented only one type of quinone, ubiquinone Q-8, as opposed to Brachymonas denitrificans which presented both ubiquinone Q-8 and rhodoquinone RQ-8 (Hiraishi et al., 1995).

Strain $23310^{\mathrm{T}}$ shared the same polar flagella morphology, optimum temperature and $\mathrm{pH}$ with $C$. terrigena (De Vos et al., 1985), but several differences were observed in the substrate range (Table 1). Differences in substrate utilization between strain $23310^{\mathrm{T}}$ and members of the genus Comamonas were found for gluconate, pyruvate, alanine, citrate, benzoate, phenylalanine and ethanol. Several substrates were also utilized, coupled to nitrate reduction under denitrifying conditions, by strains $23310^{\mathrm{T}}, \mathrm{K}$ and 6 . This result confirms the ability of these strains to perform respiratory denitrification with different substrates. According to this we can hypothesize that these strains were selected in the reactor because of the ability to couple oxidation of substrates present in the leachate with nitrate reduction, thus playing an important role in the elimination of nitrate and organic compounds.

According to the physiological and phylogenetic characteristics of strain $23310^{\mathrm{T}}$, we propose the creation of a new species within the genus Comamonas for which the name Comamonas nitrativorans is proposed.
Strain $23310^{\mathrm{T}}$ was deposited at the DSMZ as strain DSM 13191 ${ }^{\mathrm{T}}$, at the NCCB (Netherlands Culture Collection of Bacteria) as NCCB $100007^{\mathrm{T}}$ and at the CCT (Coleçao de Culturas Tropical, Brazil) as CCT $7062^{\mathrm{T}}$. The 16S rDNA sequence was deposited at EMBL (AJ251577). During the course of this work, the sequences of strain 110 (AF233876) and the closely related sequences of strains P17 (AF233880), 5.38g (AF233879), 2.99g (AF233878) and $123^{\mathrm{T}}$ (AF233877) were also deposited at EMBL (see Gumaelius et al., 2001). As these sequences showed high similarity values to the sequence of strain $23310^{\mathrm{T}}$ (97\% in a BLAST search), further phenotypic characterization is needed to determine their relatedness to $23310^{\mathrm{T}}, 6$ and $\mathrm{K}$. Moreover, DNA-DNA hybridization or another genetic techniques, such as repetitive extragenic palindromic (REP)-PCR, randomly amplified polymorphic DNA (RAPD) or ARDRA, of the 16S rDNA, ITS and part of the 23S rDNA are needed to determine if all the strains belong to the same species.

\section{Description of Comamonas nitrativorans sp. nov.}

Comamonas nitrativorans (ni.tra.ti.vo'rans. N.L. nitras nitrate; L. adj. part. vorans devouring, digesting; N.L. adj nitrativorans nitrate-consuming).

Gram-negative, curved rod-shaped cells, occurring singly or in pairs. Very motile, with two tufts of polar flagella. Oxidase-positive, catalase-positive. Colonies in TSA medium $(24 \mathrm{~h})$ are cream-coloured, circular, 1-2 mm diameter. Aerobic and chemo-organotrophic metabolism, can grow on acetate, butyrate, n-caproate, i-butyrate, i-valerate, propionate, n-valerate, lactate, alanine, benzoate, phenylalanine and ethanol. No growth is observed on sugars. Anoxic reduction of nitrate, nitrite and nitrous oxide to nitrogen. Rate of nitrogen gas production is $95 \mu \mathrm{mol} \mathrm{N}_{2} \mathrm{O} \quad(\mathrm{g}$ protein $)^{-1} \min ^{-1}$ on acetate. Optimum $\mathrm{pH}$ and temperature are 7 and $30^{\circ} \mathrm{C}$, respectively. Phylogenetically, closely related to $C$. terrigena within the family Comamonadaceae in the $\beta$-subclass of the Proteobacteria. Isolated from a denitrifying reactor from a landfill leachate treatment system in Montevideo, Uruguay. Type strain is $23310^{\mathrm{T}}$ (= DSM $13191^{\mathrm{T}}=$ NCCB $100007^{\mathrm{T}}=$ CCT $\left.7062^{\mathrm{T}}\right)$.

\section{ACKNOWLEDGEMENTS}

We thank J. I. Aguirre and S. Jurado from Universidad de la Plata, Argentina, for the electron microscopy studies. This investigation was financially supported by International Foundation for Science (IFS), by PEDECIBA-Química (a foundation for the development of basic science in Uruguay) and by CONICYT (Consejo Nacional de Investigación Científica) fondo Clemente Estable.

\section{REFERENCES}

Anders, H. J., Kaetzke, A., Kämpfer, P., Ludwig, W. \& Fuchs, G. (1995). Taxonomic position of aromatic-degrading denitrifying pseudomonad strains K 172 and KB 740 and their description 
as new members of the genera Thauera, as Thauera aromatica sp. nov., and Azoarcus, as Azoarcus evansii sp. nov., respectively, members of the beta subclass of the Proteobacteria. Int $J$ Syst Bacteriol 45, 327-333.

Borzacconi, L. (1998). Sistema de tratamiento de lixiviado de relleno sanitario. $\mathrm{PhD}$ thesis, Facultad de Ingeniería. Universidad de la República, Montevideo, Uruguay.

Christensen, S. \& Tiedje, J. M. (1988). Sub-parts-per-billion nitrate method: Use of an $\mathrm{N}_{2} \mathrm{O}$-producing denitrifier to convert $\mathrm{NO}_{3}^{-}$or ${ }^{15} \mathrm{NO}_{3}^{-}$to $\mathrm{N}_{2} \mathrm{O}$. Appl Environ Microbiol 54, 1409-1413.

Daniels, L., Hanson, R. S. \& Phillips, J. A. (1994). Chemical analysis. In Methods for General and Molecular Bacteriology, pp. 514-554. Edited by P. Gerhardt, R. G. E. Murray, W. A. Wood \& N. R. Krieg. Washington, DC: American Society for Microbiology.

De Vos, P., Kersters, K., Falsen, E., Pot, B., Gillis, M., Sergers, P. \& De Ley, J. (1985). Comamonas Davis and Park 1962 gen. nov., nom. rev. emend., and Comamonas terrigena Hugh 1962 sp. nov., nom. rev. Int J Syst Bacteriol 35, 443-453.

Felsenstein, J. (1993). PHYLIP (Phylogeny Inference Package) version $3.5 \mathrm{p}$. Seattle: Department of Genetics, University of Washington.

Fernandez, A., Huang, S., Seston, S., Xing, J., Hickey, R., Criddle, C. \& Tiedje, J. (1999). How stable is stable? Function versus community composition. Appl Environ Microbiol 65, 3697-3704.

Godon, J. J., Zumstein, E., Dabert, P., Habouzit, F. \& Moletta, R. (1997). Molecular microbial diversity in an anaerobic digestor as determined by small-subunit r-DNA sequence analysis. Appl Environ Microbiol 63, 2802-2813.

Gumaelius, L., Magnusson, G., Pettersson, B. \& Dalhammar, G. (2001). Comamonas denitrificans sp. nov., an efficient denitrifying bacterium isolated from activated sludge. Int $J$ Syst Evol Microbiol 51, 999-1006.

Hiraishi, A., Shin, Y. K. \& Sugiyama, J. (1995). Brachymonas denitrificans gen. nov., sp. nov., an aerobic chemoorganotrophic bacterium which contains rhodoquinones, and evolutionary relationships of rhodoquinone producers to bacterial species with various quinone classes. J Gen Appl Microbiol 41, 99-117. Knowles, R. (1982). Denitrification. Microbiol Rev 46, 43-70.

Koivula, T. T. \& Hantula, J. (1997). Diversity within bacterial isolates hybridizing with Comamonas probe ppT. $J$ Basic Microbiol 37, 129-137.

Kroppenstedt, R. M. (1985). Fatty acid and menaquinone analysis of actinomycetes and related organisms. In Chemical Methods in Bacterial Systematics, pp. 173-199. Edited by M. Goodfellow \& D. E. Minnikin. London: Academic Press.

Mahne, I. \& Tiedje, J. M. (1995). Criteria and methodology for identifying respiratory denitrifiers. Appl Environ Microbiol 61, $1110-1115$.

Patureau, D., Godon, J. J., Dabert, P., Bouchez, T., Bernet, N.,
Delgenes, J.P. \& Moletta, R. (1998). Microvirgula aerodenitrificans gen. nov., sp. nov., a new Gram-negative bacterium exhibiting co-respiration of oxygen and nitrogen oxides up to oxygen-saturated conditions. Int J Syst Bacteriol 48, 775-782.

Quevedo, M., Guynot, E. \& Muxí, L. (1996). Denitrifying potential of methanogenic sludge. Biotechnol Lett 18, 1363-1368.

Rainey, F. A., Kelly, D. P., Stackebrandt, E., Burkhardt, J., Hiraishi, A., Katayama, Y. \& Wood, A. (1999). A re-evaluation of the taxonomy of Paracoccus denitrificans and a proposal for the creation of Paracoccus pantotrophus comb. nov. Int J Syst Bacteriol 49, 645-651.

Robertson, L. A. \& Kuenen, J. G. (1984). Aerobic denitrification: a controversy revived. Arch Microbiol 139, 351-354.

Robertson, L. A., Van Niel, E. W. J., Torresmans, R. A. M. \& Kuenen, J. G. (1988). Simultaneous nitrification and denitrification in aerobic chemostat cultures of Thiosphaera pantotropha. Appl Environ Microbiol 54, 2812-2818.

Robertson, L. A., Cornelisse, R., De Vos, P., Hadioetomo, R. \& Kuenen, J. G. (1989). Aerobic denitrification in various heterotrophic nitrifiers. Antonie Leeuwenhoek 56, 289-299.

Robertson, L. A., Dalsgaard, T., Revsbech, N. P. \& Kuenen, J. G. (1995). Confirmation of aerobic denitrification in batch cultures, using gas chromatography and $15 \mathrm{~N}$ mass spectrometry. FEMS Microbiol Ecol 18, 113-120.

Sambrook, J., Fritsch, E. F. \& Maniatis, T. (1989). Molecular Cloning: a Laboratory Manual, 2nd edn. Cold Spring Harbor, NY: Cold Spring Harbor Laboratory.

Smibert, R. M. \& Krieg, N. R. (1994). Phenotypic characterization. In Methods for General and Molecular Bacteriology, pp. 611-651. Edited by P. Gerhardt, R. G. E. Murray, W. A. Wood \& N. R. Krieg. Washington, DC: American Society for Microbiology.

Scholten, E., Lukow, T., Auling, G., Kroppenstedt, R. M., Rainey, F. A. \& Diekman, H. (1999). Thauera mechernichensis sp. nov., an aerobic denitrifier from a leachate treatment plant. Int J Syst Bacteriol 49, 1045-1051.

Tamaoka, J., Ha, D. M. \& Komagata, K. (1987). Reclassification of Pseudomonas acidovorans den Dooren de Jong 1926 and Pseudomonas testosteroni Marcus and Talalay 1956 as Comamonas acidovorans comb. nov. and Comamonas testosteroni comb. nov., with an emended description of the genus Comamonas. Int J Syst Bacteriol 37, 52-59.

Wen, A., Fegan, M., Hayward, C., Chakraborty, S. \& Sly, L. I. (1999). Phylogenetic relationships among members of the Comamonadaceae, and description of Delftia acidovorans (den Dooren de Jong 1926 and Tamaoka et al., 1987) gen. nov., comb. nov. Int J Syst Bacteriol 49, 567-576.

Zumft, W. G. (1992). The denitrifying prokaryotes. In The Prokaryotes, 2nd edn, pp. 554-582. Edited by A. Balows, H. G. Trüper, M. Dworkin, W. Harder \& K. H. Schleifer. New York: Springer. 